\title{
Ý KIẾN PHẢN HỒI CỦA NGƯỜI DAY VÀ NGƯỜI HOC VỀ CÔNG TÁC KIỂM TRA ĐÁNH GIÁ CÁC HỌC PHẨN THƯC HÀNH TIẾNG 1A + 1B, 2A + 2B TAI KHOA NGÔN NGƯ VÃ VĂN HÓA PHÁP, TRƯỜNG ĐẠI HỌC NGOẠI NGỮ - ĐẠI HỌC QUỐC GIA HÀ NỘI
}

\author{
Đỗ Thị Bích Thủy* \\ Khoa Ngôn ngũ và Văn hóa Pháp, Trường Đại học Ngoại ngũu, ĐHQGHN, \\ Phạm Văn Đồng, Cầu Giấy, Hà Nội, Việt Nam \\ Nhận bài ngày 16 tháng 10 năm 2017 \\ Chỉnh sửa ngày 28 tháng 05 năm 2018; Chấp nhận đăng ngày 29 tháng 05 năm 2018
}

Tóm tắt: Nghiên cứu này ${ }^{1}$ giới thiệu kết quả điều tra khảo sát ý kiến phản hồi của người dạy và người học về công tác kiểm tra đánh giá các học phần Thực hành tiếng $1 \mathrm{~A}+1 \mathrm{~B}, 2 \mathrm{~A}+2 \mathrm{~B}$ năm học 2016-2017 tại Khoa Ngôn ngữ và Văn hóa Pháp, Trường Đại học Ngoại ngữ - Đại học Quốc gia Hà Nội (ĐHNN ĐHQGHN). Khảo sát cho thấy giáo viên và sinh viên có những phản hồi tích cực về công tác kiểm tra đánh giá các học phần thực hành tiếng $1 \mathrm{~A}+1 \mathrm{~B}, 2 \mathrm{~A}+2 \mathrm{~B}$, và đặc biệt đánh giá cao tính đa dạng của các phương pháp đánh giá kết quả học tập được áp dụng cũng như đánh giá cao việc kết quả học tập được trả lại cho sinh viên kịp thời để người học có những điều chỉnh phù hợp. Bài báo cũng đưa ra một số đề xuất để nâng cao hơn nữa chất lượng công tác kiểm tra đánh giá các học phần thực hành tiếng.

Tù khóa: phản hồi của người dạy, phản hồi của người học, kiểm tra đánh giá, thực hành tiếng, tiếng Pháp

\section{Dẫn nhập}

Để đảm bảo chất lượng giáo dục nói chung và kiểm tra đánh giá nói riêng, hoạt động khảo sát ý kiến các bên liên quan được coi là một công cụ vô cùng hữu ích và khách quan để cơ sở đào tạo tiếp nhận được những phản hồi đa chiều về chất lượng của hoạt động giáo dục, từ đó có kế hoạch khắc phục những tồn tại và đưa ra những cải tiến cần thiết nhằm không ngừng nâng cao chất lượng, đáp ứng tốt hơn nhu cầu của xã hội.

\footnotetext{
* ĐT.: 84-976062007

Email: dbthuy2003@gmail.com

${ }^{1}$ Nghiên cứu này được hoàn thành với sự hỗ trợ của Trường Đại học Ngoại ngữ, Đại học Quốc gia Hà Nội trong đề tài mã số N.17.04.
}

Tại ĐHNN - ĐHQGHN, Trung tâm Đảm bảo chất lượng thường xuyên tiến hành các khảo sát lấy ý kiến phản hồi của các bên liên quan về chương trình đào tạo, về chất lượng giảng dạy, về các hoạt động hỗ trợ đào tạo ở cấp trường và cấp khoa (Nguyễn Thị Minh Tâm, 2017). Tuy nhiên, ở từng học phần cụ thể, các tổ bộ môn từng khoa cũng cần tiến hành lấy ý kiến khảo sát của người học và người dạy về công tác giảng dạy, trong đó có kiểm tra đánh giá. Việc đảm bảo chất lượng của hoạt động kiểm tra đánh giá của từng môn học thành phần của chương trình đào tạo là yếu tố quyết định đến chất lượng giáo dục chung của nhà trường (Nguyễn Thị Ngọc Quỳnh, 2017). Hơn nữa, nhiều nghiên cứu cho thấy kiểm tra đánh 
giá còn tác động mạnh mẽ tới quá trình dạy và học của giáo viên và sinh viên (Nguyễn Thúy Lan, 2017).

Bài báo này trình bày một phần kết quả của đề tài nghiên cứu khoa học cấp cơ sở về công tác kiểm tra đánh giá các học phần thực hành tiếng $(\mathrm{THT}) 1 \mathrm{~A}+1 \mathrm{~B}, 2 \mathrm{~A}+2 \mathrm{~B}$ năm thứ nhất, Khoa Ngôn ngữ và Văn hóa Pháp năm học 2016-2017. Nghiên cứu này trả lời câu hỏi sau đây:

- Người dạy và người học phản hồi thế nào về công tác kiểm tra đánh giá các học phần THT $1 \mathrm{~A}+1 \mathrm{~B}, 2 \mathrm{~A}+2 \mathrm{~B}$ ở Khoa Ngôn ngữ và Văn hóa Pháp năm học 2016-2017?

- Trong bối cảnh hiện nay, cần làm gì để hoàn thiện hơn công tác kiểm tra đánh giá các học phần THT $1 \mathrm{~A}+1 \mathrm{~B}, 2 \mathrm{~A}+2 \mathrm{~B}$ ?

\section{Co’ sở lý luận}

2.1. Mối quan hệ giũa kiểm tra đánh giá và quá trình dạy và hoc

Từ những năm 1970, nhiều nghiên cứu tiến hành tại các trường đại học danh tiếng trên thế giới đã chỉ ra rằng sinh viên ở các trường này chịu tác động của quá trình kiểm tra đánh giá nhiều hơn là quá trình dạy học
(Snyder, 1971; Miller \& Parlett, 1974). Sự chuyên cần và nỗ lực học tập của sinh viên phụ thuộc rất nhiều vào yêu cầu của hệ thống kiểm tra đánh giá.

Bailey (1996) đã đưa ra mô hình lý thuyết về tác động dội ngược của kiểm tra đánh giá tới quá trình dạy và học. Mô hình này cho thấy mối quan hệ biện chứng giữa bài thi và ba thành tố là người tham gia (người học, người dạy, người thiết kế học liệu đề cương và nhà nghiên cứu), quy trình và kết quả (học, dạy, học liệu đề cương mới và kết quả nghiên cứu). Theo mô hình này, kiểm tra đánh giá sẽ tác động trực tiếp tới người tham gia, quy trình và kết quả, nhưng những phản hồi từ người tham gia, quy trình và kết quả cũng sẽ có tác động ngược trở lại điều chỉnh hoạt động kiểm tra đánh giá. Trong nghiên cứu của chúng tôi, nhà nghiên cứu cũng là nhà thiết kế học liệu đề cương và là giáo viên trực tiếp giảng dạy, muốn thu thập phản hồi của người học và người dạy về quy trình cũng như kết quả dạy và học. Kết quả của nghiên cứu chắc chắn sẽ được sử dụng để điều chỉnh hoạt động kiểm tra đánh giá, đề cương, học liệu, quá trình dạy và học trong những năm tới.

PARTICIPANTS

PRODUCTS

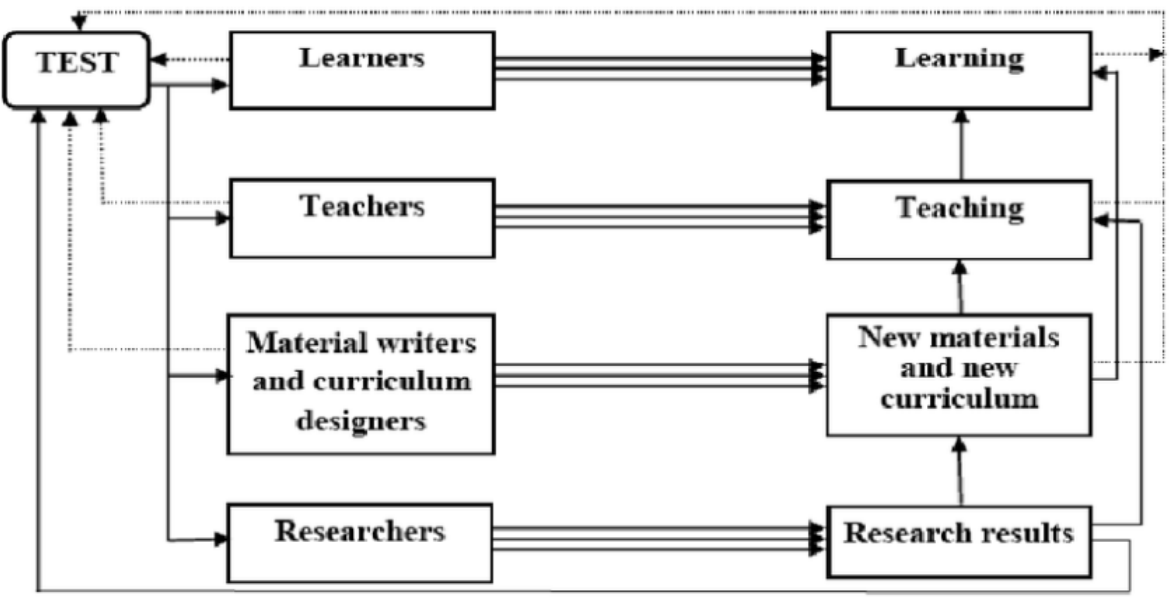

Hình 1. Mô hình tác động dội ngược của Bailey (1996) 
2.2. Tiêu chuẩn "Đánh giá kết quả học tập của nguời học" của bộ tiêu chuẩn chất luợng $A U N-Q A$

Theo Luật Giáo dục 2005, "kiểm định chất lượng giáo dục là biện pháp chủ yếu nhằm xác định mức độ thưc hiện muc tiêu, chuoong trình, nội dung giáo duc đối với nhà truờng và cơ sở giáo dục khác. Việc kiểm định chất lượng giáo duc đurợc thưc hiện định kỳ trong phạm vi cả nuớc và đối với tùng co sở giáo duc. Kết quả kiểm định chất lượng giáo dục được công bố công khai để xã họi biết và giám sát" (Điều 17). Kiểm định chất lượng được coi là yêu cầu sống còn với các trường đại học nói chung và Trường ĐHNN - ĐHQGHN nói riêng trong quá trình hội nhập vào nền giáo dục toàn cầu. Hiện nay, Bộ Giáo dục và Đào tạo đang áp dụng bộ tiêu chuẩn kiểm định chất lượng cấp chương trình đào tạo theo AUN-QA (ASEAN University Network - Quality Assurance), đồng thời đang triển khai áp dụng thí điểm bộ tiêu chuẩn đánh giá cấp trường theo AUN-QA với 25 tiêu chuẩn, 111 tiêu chí. Khoa Ngôn ngữ và Văn hóa Pháp, ĐHNN - ĐHQGHN cũng vừa áp dụng bộ tiêu chuẩn kiểm định chất lượng cấp chương trình đào tạo theo AUN-QA phiên bản 3.0 để tiến hành kiểm định chương trình đào tạo cấp ĐHQGHN năm 2017. Xuất phát từ mong muốn kết quả nghiên cứu có thể giúp xây dựng văn hóa chất lượng cho cơ sở đào tạo và giải quyết những tồn tại của thực tiễn, chúng tôi đã quyết định lựa chọn các tiêu chí kiểm tra đánh giá sinh viên của bộ tiêu chuẩn kiểm định chất lượng AUN-QA (ASEAN University Network, 2015) phiên bản 3.0 cấp chương trình đào tạo, năm 2015 là công cụ đo cho nghiên cứu của mình.

Theo AUN-QA cấp chương trình đào tạo phiên bản 3.0, đánh giá kết quả học tập của người học nằm ở tiêu chuẩn 5 và danh mục kiểm tra (checklist) gồm có 5 tiêu chí sau đây:

Bảng 1. Tiêu chuẩn "Đánh giá kết quả học tập của người học” (tiếng Anh)

\begin{tabular}{|c|c|c|c|c|c|c|c|c|}
\hline 5 & Student Assessment & 1 & 2 & 3 & 4 & 5 & 6 & 7 \\
\hline 5.1 & $\begin{array}{l}\text { The student assessment is constructively aligned } \\
\text { to the achievement of the expected learning } \\
\text { outcomes }[1,2]\end{array}$ & & & & & & & \\
\hline 5.2 & $\begin{array}{l}\text { The student assessments including timelines, } \\
\text { methods, regulations, weight distribution, rubrics } \\
\text { and grading are explicit and communicated to } \\
\text { students }[4,5]\end{array}$ & & & & & & & \\
\hline 5.3 & $\begin{array}{l}\text { Methods including assessment rubrics and } \\
\text { marking schemes are used to ensure validity, } \\
\text { reliability and fairness of student assessment [6, } \\
\text { 7] }\end{array}$ & & & & & & & \\
\hline 5.4 & $\begin{array}{l}\text { Feedback of student assessment is timely and } \\
\text { helps to improve learning [3] }\end{array}$ & & & & & & & \\
\hline 5.5 & $\begin{array}{l}\text { Students have ready access to appeal procedure } \\
\text { [8] }\end{array}$ & & & & & & & \\
\hline
\end{tabular}

Nhiều trung tâm đảm bảo chất lượng và khảo thí của một số trường đại học đã dịch bản này ra tiếng Việt, nhưng trong nghiên cứu này chúng tôi lựa chọn bản dịch của Viện Đảm bảo chất lượng giáo dục, ĐHQGHN, là nơi đã tổ chức tập huấn cho cán bộ tham gia công tác kiểm định chất lượng ĐHNN - ĐHQGHN (Tài liệu giới thiệu bộ tiêu chuẩn đánh giá chương trình đào tạo của Bộ Giáo dục và Đào tạo theo thông tư 04/2016/TT-BGDĐT.) 
Bảng 2. Tiêu chuẩn "Đánh giá kết quả học tập của người học" (tiếng Việt)

\begin{tabular}{|c|c|}
\hline $\mathbf{5}$ & Đánh giá kết quả học tập của người học \\
\hline 5.1 & $\begin{array}{c}\text { Việc đánh giá kết quả học tập của người học được thiết kế phù hợp với mức độ đạt được chuẩn } \\
\text { đầu ra. }\end{array}$ \\
\hline 5.2 & $\begin{array}{c}\text { Các quy định về đánh giá kết quả học tập của người học (bao gồm thời gian, phương pháp, tiêu } \\
\text { chí, trọng số, cơ chế phản hồi và các nội dung liên quan) rõ ràng và được thông báo công khai tới } \\
\text { người học). }\end{array}$ \\
\hline 5.3 & \begin{tabular}{c} 
Phương pháp đánh giá kết quả học tập đa dạng, đảm bảo độ giá trị, độ tin cậy và sự công bằng. \\
\hline 5.4
\end{tabular}$\quad$ Kết quả đánh giá được phản hồi kịp thời để người học cải thiện việc học tập. \\
\hline 5.5 & Người học tiếp cận dễ dàng với quy trình khiếu nại về kết quả học tập. \\
\hline
\end{tabular}

So với phiên bản 2.0, số lượng các tiêu chí giảm từ 7 xuống còn 5 , một số tiêu chí mới xuất hiện trong phiên bản 3.0 như đảm bảo tính công bằng, phản hồi phải kịp thời hay tiếp cận với quy trình phúc tra khiếu nại trong kiểm tra đánh giá. Điều này thể hiện phiên bản 3.0 quan tâm nhiều hơn tới người học và quá trình học.

\subsection{Thưc trạng kiểm tra đánh giá môn THT} năm thứ nhất tại Khoa Ngôn ngũ và Văn hóa Pháp, ĐHNN - ĐHQGHN

Tất cả các bài kiểm tra đánh giá học phần THT năm thứ nhất tại Khoa Ngôn ngữ và Văn hóa Pháp đều dựa trên khung tham chiếu chung châu Âu (cadre européen commun de référence pour les langues, thường viết tắt theo tiếng Anh là CEFR) (Conseil de l'Europe, 2001; Tagliante, 2005) và dựa trên chuẩn đầu ra của môn học. Bài kiểm tra và thi không chỉ đo kiến thức Ngữ âm, Từ vựng, Ngữ pháp mà cả các kĩ năng Nghe, Nói, Đọc, Viết. Thái độ học tập tích cực của sinh viên cũng được cộng điểm thưởng vào phần điểm kiểm tra thường xuyên. Chuẩn đầu ra môn học, nội dung giảng dạy, nội dung và hình thức kiểm tra đánh giá được trình bày rõ ràng trong đề cương môn học, được cập nhật từng năm và được cố vấn học tập chuyển tới sinh viên ngay đầu năm học.

Kiểm tra đánh giá luôn gắn với nội dung đã được giảng dạy trong môn học và khá đa dạng về hình thức.
Các bài kiểm tra thường xuyên do giáo viên tự quyết định hình thức và thời điểm, có thể là kiểm tra kiến thức hay kĩ năng giao tiếp. Nhiều giáo viên hay ưu tiên kiểm tra kĩ năng sản sinh Nói hay Viết để lấy điểm thường xuyên vì hình thức này cho phép đánh giá toàn diện cả kiến thức ngôn ngữ, kiến thức văn hóa xã hội, kĩ năng giao tiếp của sinh viên.

Các bài kiểm tra minitest về ngữ pháp từ vựng đều dưới dạng trắc nghiệm khách quan 4 lựa chọn giúp các em làm quen với định dạng bài thi chuẩn đầu ra tốt nghiệp THT bậc 5 theo Khung năng lực ngoại ngữ dùng cho Việt Nam.

Các bài giữa kì và cuối kì kết hợp cả trắc nghiệm khách quan và tự luận theo định dạng bài thi DELF của Khung tham chiếu chung châu Âu (CEFR) dùng cho tiếng Pháp.

Định dạng bài thi giữa kì và cuối kì được công bố trong đề cương môn học $1 \mathrm{~A}+1 \mathrm{~B}, 2 \mathrm{~A}$ $+2 \mathrm{~B}$. Ma trận bài kiểm tra minitest về Ngữ pháp, Từ vựng đã được xây dựng và hoàn thiện dần dần, bám sát nội dung dạy và học trong từng chuyên đề. Nội dung ôn tập môn Viết và Nói được cố vấn học tập chuyển tới sinh viên trước kì thi.

Trong đề cương môn học cũng nêu rõ bài kiểm tra phải được trả lại cho sinh viên chậm nhất là một tuần sau khi tiến hành kiểm tra. 


\section{Phương pháp nghiên cứu}

Để có được một đánh giá khách quan về công tác kiểm tra đánh giá các học phần $1 \mathrm{~A}+$ 1B, 2A + 2B năm học 2016-2017, chúng tôi đã tiến hành một khảo sát lấy ý kiến người dạy và người học. Toàn thể giáo viên dạy các học phần $1 \mathrm{~A}+1 \mathrm{~B}, 2 \mathrm{~A}+2 \mathrm{~B}$ năm thứ nhất và toàn thể sinh viên năm thứ nhất đã được phát phiếu điều tra vào tuần học cuối của năm học 2016-2017.

Phiếu điều tra gồm có 18 câu hỏi chia thành ba phần (xem phụ lục). Phần thứ nhất gồm 4 câu hỏi (1-4) có mục tiêu đảm bảo người được khảo sát nắm được các khái niệm như chuẩn đầu ra, các quy định về kiểm tra đánh giá, nội dung kiến thức và kĩ năng các học phần THT.

Phần thứ hai gồm 12 câu hỏi (5-16) được xây dựng dựa trên các tiêu chí kiểm tra đánh giá của AUN-QA phiên bản 3.0 cấp chương trình đào tạo, năm 2015. Chúng tôi đã đề nghị người được khảo sát đánh giá công tác kiểm tra đánh giá các học phần THT $1 \mathrm{~A}+1 \mathrm{~B}, 2 \mathrm{~A}$ $+2 \mathrm{~B}$ theo bốn mức độ: rất tốt, tốt, trung bình, kém. Chúng tôi có một chút chỉnh sửa khi áp dụng bộ tiêu chí này để viết bảng câu hỏi cho nghiên cứu này. Tiêu chí 5.3 được chúng tôi tách thành 3 câu hỏi:

- Phương pháp đánh giá kết quả học tập có đa dạng không?

- Phương pháp đánh giá kết quả học tập có đảm bảo độ giá trị, độ tin cậy không?

- Phương pháp đánh giá kết quả học tập có đảm bảo sự công bằng không?

Tiêu chí 5.5 chúng tôi không sử dụng trong bảng hỏi vì quy trình khiếu nại về kết quả học tập rất ít khi diễn ra và thuộc về quy chế chung cho toàn bộ các khoa trong trường, không thuộc quyền quản lý cấp bộ môn như các tiêu chí khác.

Phần thứ ba là 2 câu hỏi mở (17-18) để người dạy và người học đưa ra những đánh giá và đề xuất riêng của mình nhằm nâng cao chất lượng công tác kiểm tra đánh giá.
Tổng cộng chúng tôi đã thu về được 8 phiếu trả lời của giáo viên và 101 phiếu trả lời của sinh viên. Các giáo viên được mã hóa từ G1 đến G8, các sinh viên được mã hóa theo lớp, từ F1P.1 đến F6.20.

\section{Kết quả nghiên cứu}

4.1. Phản hồi của người dạy và người học về việc lĩnh hộ đề cuơng và lịch trình môn học (câu hỏi 1 đến 4)

Các thông tin về kiểm tra đánh giá được thông báo tới người học từ đầu năm trong đề cương môn học. Nội dung học và lịch thi cụ thể cũng đã được ấn định từ đầu năm học trong lịch trình giảng dạy môn học, được chuyển tới sinh viên qua kênh của cố vấn học tập. Khi họp bộ môn, tổ cũng thường xuyên nhấn mạnh với giáo viên trong tuần đầu năm học cần giới thiệu tới các em những tài liệu này và tổ có kiểm tra với từng lớp trưởng xem lớp đã nhận được các tài liệu chưa.

$100 \%$ giáo viên đều trả lời "Có" cho câu hỏi từ 1 đến 4 , nghĩa là tất cả giáo viên đều đã đọc đề cương lịch trình các học phần THT $1 \mathrm{~A}$ $+1 \mathrm{~B}, 2 \mathrm{~A}+2 \mathrm{~B}$ và đều nắm được các khái niệm sẽ được hỏi tới trong các câu hỏi từ 5 đến 16 .

Đại đa số sinh viên cũng đều trả lời đã đọc đề cương lịch trình môn học, chỉ có 5 trên 101 sinh viên trả lời là không đọc đề cương lịch trình, lý do là nhà không có mạng, vì dài quá, vì học lần lượt rồi, vì các thầy cô vẫn chuẩn bị đầy đủ bài giảng và nhắc chuẩn bị bài. Đáng chú ý là $4 / 5$ sinh viên này nằm ở cùng một lớp, lớp F4. Có lẽ giáo viên cần giúp sinh viên nâng cao tính chủ động hơn nữa trong việc làm chủ các tài liệu hỗ trợ học tập.

4.2. Phản hồi của người dạy và người học về công tác kiểm tra đánh giá (câu hỏi 5 đến 16)

Dưới đây là bảng tổng hợp kết quả điều tra ý kiến phản hồi của người dạy và người học về công tác kiểm tra đánh giá học phần THT $1 \mathrm{~A}+1 \mathrm{~B}$ và $2 \mathrm{~A}+2 \mathrm{~B}$. 
Bảng 3. Tổng hợp ý kiến phản hồi của người dạy và người học

\begin{tabular}{|c|c|c|c|c|c|c|c|c|c|}
\hline Câu hỏi & $\begin{array}{c}\text { Rất Tốt } \\
\text { (ng.) }\end{array}$ & $\begin{array}{c}\text { Rất Tốt } \\
(\%)\end{array}$ & $\begin{array}{l}\text { Tốt } \\
\text { (ng.) }\end{array}$ & $\begin{array}{l}\text { Tốt } \\
(\%)\end{array}$ & $\begin{array}{c}\text { Tống Rất Tốt và Tốt } \\
(\%)\end{array}$ & $\begin{array}{c}\text { TB } \\
\text { (ng.) }\end{array}$ & $\begin{array}{c}\text { TB } \\
(\%)\end{array}$ & $\begin{array}{l}\text { Kém } \\
\text { (ng.) }\end{array}$ & $\begin{array}{l}\text { Kém } \\
(\%)\end{array}$ \\
\hline GV-câu 5 & 2 & $25 \%$ & 5 & $63 \%$ & $88 \%$ & 1 & $13 \%$ & 0 & $0 \%$ \\
\hline GV-câu 6 & 2 & $25 \%$ & 5 & $63 \%$ & $88 \%$ & 1 & $13 \%$ & 0 & $0 \%$ \\
\hline SV-câu 5 & 10 & $10 \%$ & 85 & $84 \%$ & $94 \%$ & 6 & $6 \%$ & 0 & $0 \%$ \\
\hline SV-câu 6 & 10 & $10 \%$ & 86 & $85 \%$ & $95 \%$ & 5 & $5 \%$ & 0 & $0 \%$ \\
\hline GV-câu 7 & 2 & $25 \%$ & 5 & $63 \%$ & $88 \%$ & 1 & $13 \%$ & 0 & $0 \%$ \\
\hline GV-câu 8 & 2 & $25 \%$ & 5 & $63 \%$ & $88 \%$ & 1 & $13 \%$ & 0 & $0 \%$ \\
\hline SV-câu 7 & 13 & $13 \%$ & 73 & $72 \%$ & $85 \%$ & 15 & $15 \%$ & 0 & $0 \%$ \\
\hline SV-câu 8 & 13 & $13 \%$ & 76 & $75 \%$ & $88 \%$ & 12 & $12 \%$ & 0 & $0 \%$ \\
\hline GV-câu 9 & 5 & $63 \%$ & 3 & $38 \%$ & $100 \%$ & 0 & $0 \%$ & 0 & $0 \%$ \\
\hline GV-câu 10 & 5 & $63 \%$ & 3 & $38 \%$ & $100 \%$ & 0 & $0 \%$ & 0 & $0 \%$ \\
\hline SV-câu 9 & 15 & $15 \%$ & 76 & $75 \%$ & $90 \%$ & 10 & $10 \%$ & 0 & $0 \%$ \\
\hline SV-câu 10 & 19 & $19 \%$ & 74 & $73 \%$ & $92 \%$ & 8 & $8 \%$ & 0 & $0 \%$ \\
\hline GV-câu 11 & 3 & $38 \%$ & 4 & $50 \%$ & $88 \%$ & 1 & $13 \%$ & 0 & $0 \%$ \\
\hline GV-câu 12 & 3 & $38 \%$ & 4 & $50 \%$ & $88 \%$ & 1 & $13 \%$ & 0 & $0 \%$ \\
\hline SV-câu 11 & 17 & $17 \%$ & 78 & $77 \%$ & $94 \%$ & 6 & $6 \%$ & 1 & $1 \%$ \\
\hline SV-câu 12 & 17 & $17 \%$ & 75 & $74 \%$ & $91 \%$ & 9 & $9 \%$ & 1 & $1 \%$ \\
\hline GV-câu 13 & 4 & $50 \%$ & 4 & $50 \%$ & $100 \%$ & 0 & $0 \%$ & 0 & $0 \%$ \\
\hline GV-câu 14 & 4 & $50 \%$ & 4 & $50 \%$ & $100 \%$ & 0 & $0 \%$ & 0 & $0 \%$ \\
\hline SV-câu 13 & 11 & $11 \%$ & 72 & $71 \%$ & $82 \%$ & 18 & $18 \%$ & 1 & $1 \%$ \\
\hline SV-câu 14 & 11 & $11 \%$ & 71 & $70 \%$ & $81 \%$ & 19 & $19 \%$ & 1 & $1 \%$ \\
\hline GV-câu 15 & 2 & $25 \%$ & 6 & $75 \%$ & $100 \%$ & 0 & $0 \%$ & 0 & $0 \%$ \\
\hline GV-câu 16 & 2 & $25 \%$ & 6 & $75 \%$ & $100 \%$ & 0 & $0 \%$ & 0 & $0 \%$ \\
\hline SV-câu 15 & 23 & $23 \%$ & 71 & $70 \%$ & $93 \%$ & 7 & $7 \%$ & 1 & $1 \%$ \\
\hline SV-câu 16 & 23 & $23 \%$ & 70 & $69 \%$ & $92 \%$ & 8 & $8 \%$ & 0 & $0 \%$ \\
\hline
\end{tabular}

GV: giáo viên; SV: sinh viên

Câu 5 và 6 hỏi về việc đánh giá kết quả học tập có được thiết kế dựa trên chuẩn đầu ra môn hoc

Kết quả trả lời cho cả hai học phần là giống nhau, 2 trên 8 giáo viên đánh giá ở mức độ 4 là mức độ "Rất tốt", có 5 giáo viên đánh giá ở mức độ 3 là mức độ "Tốt" và 1 giáo viên đánh giá ở mức độ 2 là “Trung bình".

Kết quả ở sinh viên cũng gần như là giống nhau cho cả hai học phần THT, chỉ duy nhất có 1 sinh viên lớp $\mathrm{F} 6$ chọn số 2 cho học phần THT $1 \mathrm{~A}+1 \mathrm{~B}$, và chọn số 3 cho học phần $2 \mathrm{~A}$ $+2 \mathrm{~B}$. Cần lưu ý là lớp $\mathrm{F} 6$ là lớp thử nghiệm một chương trình riêng, không theo lịch trình giảng dạy chung của tổ, đặc biệt là ở thời gian đầu năm học. Trong tổng số 101 sinh viên, có 10 sinh viên cho rằng việc đánh giá kết quả học tập được thiết kế dựa trên CĐR của môn học ở cấp độ 4 "Rất Tốt", 6-5 sinh viên ở mức độ 2 “Trung bình", còn lại chọn cấp độ số 3 "Tốt".

Câu 7 và 8 hỏi về các quy định về đánh giá kết quả học tập môn học của người học (bao gồm thời gian, phwơng pháp, tiêu chí, trọng số, dạng thức, nội dung) là rõ ràng và được thông báo công khai tới người hoc.

Kết quả trả lời cho cả hai học phần là giống nhau, 2 trên 8 giáo viên đánh giá ở mức độ 4 là mức độ "Rất tốt", có 5 giáo viên đánh giá ở mức độ 3 là mức độ "Tốt” và 1 giáo viên đánh giá ở mức độ 2 là “Trung bình”. 
Có 13 sinh viên chọn cấp độ 4 "Rất Tốt" cho cả hai câu hỏi 7 và 8 về các quy định về đánh giá kết quả học tập môn học THT của người học là rõ ràng và được thông báo công khai tới người học. 74 sinh viên chọn cấp độ 3 "Tốt" cho học phần $1 \mathrm{~A}+1 \mathrm{~B}$ và 76 sinh viên chọn cấp độ 3 cho học phần $2 \mathrm{~A}+2 \mathrm{~B}$. Có 15 sinh viên chọn mức 2 “Trung bình' cho học phần $1 \mathrm{~A}+1 \mathrm{~B}$ và 12 sinh viên chọn mức độ 2 cho học phần $2 \mathrm{~A}+2 \mathrm{~B}$. Có 1 sinh viên chọn mức 1 "Kém" cho học phần $2 \mathrm{~A}+2 \mathrm{~B}$. Lý do của sự chênh lệch nhẹ này có thể là vì ở học phần $2 \mathrm{~A}+2 \mathrm{~B}$, rút kinh nghiệm của học phần $1 \mathrm{~A}+1 \mathrm{~B}$, tổ tiếng Pháp 1 đã đưa ra những quy định cụ thể hơn về nội dung ôn tập cho các bài thi minitest cũng như nội dung ôn tập Nói và Viết cuối kì. Em sinh viên duy nhất chọn mức 1 cũng phàn nàn về việc đề cương và lịch trình môn học không được phổ biến. công khai tới sinh viên. Có thể vì một nguyên nhân khách quan như thay đổi địa chỉ email, em sinh viên này đã không nhận được đề cương lịch trình ở học kì 2, do đó không nắm được các quy định về đánh giá kết quả học tập môn học.

Câu 9 và 10 hỏi về tính đa dạng của các phuơng pháp đánh giá kết quả học tập môn hoc (kiểm tra thuờng xuyên, kiểm tra giũ̃a kì, thi cuối kì, trắc nghiệm khách quan, tụ luận...).

Kết quả trả lời cho cả hai học phần là giống nhau và có kết quả 100\% từ mức "Tốt" trở lên, 5 trên 8 giáo viên đánh giá ở mức độ 4 là mức độ "Rất tốt", có 3 giáo viên đánh giá ở mức độ 3 là mức độ "Tốt".

Ở cả sinh viên, hai câu hỏi này cũng nhận được những phản hồi rất tích cực. Hơn $90 \%$ số sinh viên được hỏi chọn mức "Tốt" trở lên. Sinh viên đánh giá kết quả tính đa dạng của các phương pháp kiểm tra đánh giá ở học phần $2 \mathrm{~A}$ và $2 \mathrm{~B}$ tốt hơn một chút so với học phần $1 \mathrm{~A}$ và $1 \mathrm{~B}$. Có 19 sinh viên chọn mức điểm cao nhất cấp độ 4 "Rất Tốt", và 8 sinh viên chọn cấp độ 2 "Trung bình” cho học phần $2 \mathrm{~A}$
$+2 \mathrm{~B}$, trong khi có 15 sinh viên chọn cấp độ 4 và 10 sinh viên chọn cấp độ 2 cho học phần $1 \mathrm{~A}+1 \mathrm{~B}$.

Thực ra ở cả hai học phần $1 \mathrm{~A}+1 \mathrm{~B}, 2 \mathrm{~A}+$ $2 \mathrm{~B}$, hình thức và số lượng của các bài kiểm tra là tương đối giống nhau, đều có kiểm tra thường xuyên do giáo viên từng lớp tự quyết định, có hai bài minitest về từ vựng ngữ pháp chung cho cả khối, có một bài kiểm tra giữa kì 4 kĩ năng và một bài kiểm tra cuối kì 4 kĩ năng chung cho cả khối. Nhưng có vẻ như sang học kì hai, sinh viên đã quen dần với các hình thức kiểm tra đánh giá và được chuẩn bị tâm lý tốt hơn nên phản hồi của một số em trở nên tích cực hơn.

Câu 11 và 12 hỏi về các bài kiểm tra có đảm bảo kiểm tra được nhũng kĩ năng và kiến thức đã được day và học.

Kết quả trả lời cho cả hai học phần là giống nhau, 3 trên 8 giáo viên đánh giá ở mức độ 4 là mức độ "Rất tốt", có 4 giáo viên đánh giá ở mức độ 3 là mức độ “Tốt", và 1 giáo viên đánh giá ở mức độ 2 là "Trung bình”.

Kết quả ở sinh viên cũng gần như là giống nhau cho cả hai học phần THT. Trong tổng số 101 sinh viên, có 17 sinh viên cho rằng các bài kiểm tra THT ở cả hai học kì đảm bảo kiểm tra được những kĩ năng và kiến thức đã được dạy và học ở cấp độ 4 "Rất Tốt", 1 sinh viên chọn cấp độ 1 "Kém”. Có 6 sinh viên chọn mức độ 2 "Trung bình" cho học phần $1 \mathrm{~A}+1 \mathrm{~B}$ và 9 sinh viên chọn mức độ này cho học phần $2 \mathrm{~A}+2 \mathrm{~B}$, còn lại 78 sinh viên chọn cấp độ số 3 "Tốt" cho học kì I và 75 sinh viên chọn cấp độ này cho học kì II.

Câu 13 và 14 hỏi về các bài kiểm tra môn hoc có đảm bảo tính công bằng giữa các sinh viên hay không.

Kết quả trả lời cho cả hai học phần là giống nhau, 4 trên 8 giáo viên đánh giá ở mức độ 4 là mức độ "Rất tốt", có 4 giáo viên đánh giá ở mức độ 3 là mức độ "Tốt". 
Kết quả ở sinh viên cũng gần như là giống nhau cho cả hai học phần THT. Trong tổng số 101 sinh viên, có 11 sinh viên cho rằng các bài kiểm tra THT ở cả hai học kì năm thứ nhất đảm bảo tính công bằng giữa các sinh viên ở cấp độ 4 "Rất Tốt", 1 sinh viên chọn cấp độ 1 "Kém". Có 18 sinh viên chọn mức độ 2 "Trung bình" cho học phần $1 \mathrm{~A}+1 \mathrm{~B}$ và 19 sinh viên chọn mức độ này cho học phần $2 \mathrm{~A}$ $+2 \mathrm{~B}$, còn lại 72 sinh viên chọn cấp độ số 3 "Tốt" cho học kì I và 71 sinh viên chọn cấp độ này cho học kì II. Như vậy có một sự khác biệt khá lớn giữa phản hồi của giáo viên và của sinh viên về việc đảm bảo tính công bằng. Chúng ta sẽ cùng xem xét kĩ hơn trong phần Diễn giải và đề xuất.

Hai câu 15 và 16 hỏi về kết quả đánh giá môn hoc được trả lại cho sinh viên kịp thời để người hoc cải thiện việc học tập

Kết quả trả lời cho cả hai học phần là giống nhau, 2 trên 8 giáo viên cho rằng kết quả đánh giá môn học được trả lại cho sinh viên kịp thời để người học cải thiện việc học tập ở mức độ 4 là mức độ "Rất tốt", có 6 giáo viên đánh giá ở mức độ 3 là mức độ "Tốt".

Vậy sinh viên phản hồi thế nào về vấn đề này?

Kết quả ở sinh viên cũng gần như là giống nhau cho cả hai học phần THT. Trong tổng số 101 sinh viên, có 23 sinh viên cho rằng các bài kiểm tra THT ở cả hai học kì năm thứ nhất được trả lại cho sinh viên kịp thời để người học cải thiện việc học tập ở cấp độ 4 "Rất Tốt". Có 71 sinh viên chọn cấp độ số 3 "Tốt" cho học kì I và 70 sinh viên chọn cấp độ này cho học kì II. Có 7 sinh viên chọn mức độ 2 "Trung bình" cho học phần $1 \mathrm{~A}+1 \mathrm{~B}$ và 8 sinh viên chọn mức độ này cho học phần $2 \mathrm{~A}+2 \mathrm{~B}$. Có 1 sinh viên chọn mức độ 1 "Kém" cho học phần $1 \mathrm{~A}+1 \mathrm{~B}$ và không có sinh viên nào chọn mức này cho học phần $2 \mathrm{~A}+2 \mathrm{~B}$.
4.3. Đánh giá, đề xuất của người dạy và người học (câu hỏi 17, 18)

Cuối cùng, chúng tôi có hai câu hỏi mở để người dạy và người học đưa ra những đánh giá và đề xuất riêng của mình nhằm nâng cao chất lượng công tác kiểm tra đánh giá.

Câu hỏi 17: Nếu kết quả các bài kiểm tra hay thi của sinh viên chua tốt nhu thầy cô/ em mong muốn, xin cho biết lí do là vì sao (số 1 là lí do quan trọng nhất)

Theo giáo viên, có những nguyên nhân sau đây dẫn tới kết quả bài thi chưa tốt: ý thức tự học và ôn tập của một số sinh viên chưa cao, sinh viên chưa nắm vững kiến thức và sinh viên không có hứng thú học.

Phản hồi của sinh viên có những điểm giống và khác với giáo viên. Lý do đầu tiên sinh viên đưa ra để giải thích vì sao bài kiểm tra hay thi chưa tốt như các em mong muốn là do hơn một phần tư các em (26/101 sinh viên) tự thấy mình chưa chăm học. Lý do tiếp theo là một số em cho rằng mình chưa nắm chắc kiến thức ngữ pháp từ vựng đã học trên lớp (15/101 sinh viên) dẫn tới kết quả thi chưa tốt. Một điều chúng tôi khá bất ngờ là lý do đứng ở vị trí số 3 là do sinh viên bận làm thêm hay bận sinh hoạt câu lạc bộ sinh viên (6 sinh viên).

Chỉ có 4 sinh viên cho rằng kết quả chưa tốt là do mình chưa có hứng thú với môn học, và 2 sinh viên cho rằng do lượng kiến thức nhiều. Ngoài ra, 4 sinh viên giải thích là do mình chưa ôn kĩ bài, 3 sinh viên cho rằng mình Nghe Nói hay Phát âm chưa tốt, 3 sinh viên đưa lí do ít tiếp xúc với người nước ngoài, 3 sinh viên chưa có phương pháp học, 2 sinh viên còn mất tập trung và 1 sinh viên do nhầm với tiếng Anh.

Vậy dường như là giáo viên và sinh viên có chung lời giải thích về kết quả thi chưa tốt như mong muốn, là do một số sinh viên chưa chăm học hoặc chưa nắm vững kiến thức. Tuy 
nhiên về nguyên nhân sinh viên không có hứng thú học làm ảnh hưởng kết quả thi, chỉ có 4 sinh viên trên tổng số 101 sinh viên đưa ra nhận định này.

Câu hỏi 18: Thầy cô/ em có các đề xuất gi liên quan đến kiểm tra đánh giá

Các giáo viên được hỏi có đưa ra hai đề xuất sau:

- Giáo viên chủ động cho sinh viên làm bài kiểm tra thường xuyên để giúp quản lý tốt hơn việc học của sinh viên và giúp sinh viên gỡ điểm;

- Các giáo viên cùng dạy một lớp cần phối hợp để có nhiều đầu điểm đánh giá sinh viên theo cùng một tiêu chí.

Sinh viên được hỏi đã đưa ra những đề xuất sau:

* Nhóm các đề xuất về công tác giảng dạy:

- Nên chú trọng vào kỹ năng Nghe, Nói và Viết;

- Cần thêm phần cơ sở vật chất (máy chiếu,...). Đề xuất này đã được nhà trường thực hiện trong năm học 2017-2018;

- Giáo viên nên thường xuyên kiểm tra bài cũ của sinh viên và nghiêm khắc hơn với việc không trả bài cũ đầy đủ của sinh viên, vì sinh viên năm thứ nhất ý thức tự giác chưa cao;

- Sinh viên năm thứ nhất thường không quản lý được thời gian, thường thức rất khuya nên có thể lùi thời gian học sáng muộn hơn 30 phút đến một tiếng, tránh tình trạng ngủ gật trong giờ.

* Nhóm các đề xuất về kiểm tra đánh giá:

- Có các bài kiểm tra dạng tương tự như DELF, DALF để học sinh làm quen dần;

- Nên ôn tập lại kiến thức cho sinh viên trước khi thi;

- Bài học và bài kiểm tra nên gần gũi và liên quan đến nhau hơn nữa;

- Coi thi chặt chẽ hơn;
- Giáo viên cần hỗ trợ nhiều hơn trong bài thi nói của sinh viên;

- Cách thi nói cuối kỳ I khiến học sinh thêm mệt mỏi và lo lắng. Khoa nên chia ca để sinh viên biết giờ thi và có sự chuẩn bị tốt hơn.

\section{Diễn giải và đề xuất}

Trong phần này, chúng tôi sẽ phân tích một số kết quả tiêu biểu thu được qua khảo sát, phân tích sự khác biệt giữa phản hồi của giáo viên và của sinh viên. Cuối cùng, chúng tôi sẽ đưa ra một số đề xuất nhằm làm tốt hơn nữa công tác kiểm tra đánh giá các học phần THT.

Như vậy, chúng ta có thể thấy là ở tất cả các câu hỏi, phản hồi của giáo viên và sinh viên về công tác kiểm tra đánh giá các học phần THT $1 \mathrm{~A}+1 \mathrm{~B}, 2 \mathrm{~A}+2 \mathrm{~B}$ năm học 2016-2017 đều khá tích cực. Số các câu trả lời chọn cấp độ 3 và 4 "Tốt" và "Rất Tốt" dao động từ $88 \%$ đến $100 \%$ ở giáo viên và từ $81 \%$ đến $95 \%$ ở sinh viên. Kết quả này cũng đi cùng hướng với kết quả khảo sát ý kiến phản hồi các bên liên quan về chương trình đào tạo tại ĐHNN - ĐHQGHN của Nguyễn Thị Minh Tâm (2017) cho thấy các phương pháp kiểm tra đánh giá sử dụng được đánh giá rất cao về tính phù hợp, cập nhật, tính công khai, minh bạch $(85,9 \%)$.

Hai tiêu chí nhận được sự đánh giá cao ở cả sinh viên và giáo viên là kết quả học tập được trả lại cho sinh viên kịp thời để người học cải thiện việc học tập (câu hỏi 15-16, $100 \%$ giáo viên chọn mức "Tốt" và "Rất Tốt" cho tiêu chí này, và $92,5 \%$ sinh viên chọn mức "Tốt" và "Rất Tốt"); và tính đa dạng của các phương pháp đánh giá kết quả học tập (câu hỏi 9-10, 100\% giáo viên chọn mức "Tốt" và "Rất Tốt", và $91 \%$ sinh viên chọn mức "Tốt" và "Rất Tốt"). Nhiều kết quả nghiên cứu đã cho thấy việc trả lại bài thi nếu chậm trễ sẽ có thể không còn tác dụng hỗ trợ sinh viên vì lúc đó sinh viên đã chuyển sang nội dung học tập khác và không còn nhớ quá trình làm bài kiểm tra nữa (Gibbs and Simpson, 2005). Ý thức được điều này, trong đề cương các học 
phần THT $1 \mathrm{~A}+1 \mathrm{~B}, 2 \mathrm{~A}+2 \mathrm{~B}$ chúng tôi có yêu cầu giáo viên trả lại bài kiểm tra cho sinh viên chậm nhất là một tuần sau khi kiểm tra, và trong các cuộc họp chuyên môn, tổ bộ môn cũng lưu ý giáo viên quan tâm tới vấn đề này.

Các phương pháp kiểm tra đánh giá cũng không ngừng được cập nhật bổ sung đa dạng hóa. Nếu cách đây 3-4 năm, các bài thi và kiểm tra chủ yếu dựa trên định dạng thi DELF với 4 kĩ năng Nghe Nói Đọc Viết thì đến nay đã đưa thêm những bài kiểm tra từ vựng ngữ pháp dưới dạng trắc nghiệm khách quan để giúp sinh viên không bỡ ngỡ khi làm bài thi chuẩn đầu ra bậc 5 môn THT. Số lượng đầu điểm là khá nhiều, đòi hỏi giáo viên nhiều công sức hơn nhưng cũng giúp đánh giá không chỉ đầu ra mà cả quá trình học của sinh viên, giúp giáo viên thu thập được thông tin để điều chỉnh quá trình giảng dạy (Perrenoud, 1998; Nguyễn Quang Thuấn, 2002).

Câu hỏi 13 và 14 (về đảm bảo tính công bằng giữa các sinh viên) có một sự khác biệt khá lớn giữa phản hồi của người dạy và người học. Đây là câu hỏi nhận được sự phản hồi thấp nhất của sinh viên và cao nhất của giáo viên. Thật vậy, $81 \%$ số sinh viên được hỏi chọn cấp độ "Tốt" và "Rất Tốt", trong khi $100 \%$ giáo viên hài lòng với vấn đề công bằng giữa các sinh viên. Như vậy là dù tổ đã làm mã đề cho bài thi trắc nghiệm khách quan để tránh gian lận trong thi cử thì sinh viên vẫn có ý kiến đề nghị giáo viên coi thi chặt hơn, hay đề nghị giáo viên hợp tác hơn trong bài thi Nói. Đây cũng là vấn đề mà giáo viên cần xem xét thấu đáo hơn để tạo một môi trường thi cử công bằng hơn nữa cho sinh viên.

Từ kết quả điều tra thực trạng công tác kiểm tra đánh giá trên, chúng tôi xin đề xuất một số biện pháp nhằm nâng cao hơn nữa chất lượng công tác kiểm tra đánh giá các học phần THT.

- Hơn 1/4 số sinh viên được hỏi tự nhận kết quả kiểm tra đánh giá chưa tốt như mong muốn là do các em chưa chăm học, khoa có thể kết hợp với câu lạc bộ sinh viên tổ chức một buổi thảo luận về chủ đề này có sự tham dự của các giáo viên. Các em sẽ có một diễn đàn để cùng tìm hiểu vì sao mình chưa chăm và đưa ra những giải pháp để các em chiến thắng được “căn bệnh" lười học.

- Có $15 \%$ sinh viên nói chưa nắm vững kiến thức đã được dạy nên kết quả thi chưa tốt. Việc sinh viên chưa nắm vững kiến thức có nhiều nguyên nhân, nhưng có lẽ giáo viên cũng cần hoàn thiện tốt hơn bài giảng của mình và tăng thời lượng thực hành hơn nữa để các em có thể nắm chắc kiến thức trước khi chuyển sang dạy một kiến thức mới. Về đề cương môn học, năm học 2017-2018, tổ tiếng Pháp 1 đã có điều chỉnh theo hướng giảm bớt lượng kiến thức, tăng thời gian thực hành để các em nắm vững kiến thức tốt hơn.

- Làm tốt hơn nữa công tác thông tin tuyên truyền đối với sinh viên, đặc biệt là sinh viên năm thứ nhất, về đề cương môn học và tầm quan trọng của việc nắm chắc các thông tin trong đề cương môn học, nhất là phần liên quan tới nội dung và các hình thức kiểm tra đánh giá trong đề cương môn học.

- Ngoài đề cương môn học, nên có nội dung ôn tập cụ thể chi tiết hơn nữa về lượng từ vựng, ngữ pháp, các chủ đề và loại bài thi cho kĩ năng Nói, Viết để sinh viên có thể ôn tập tốt hơn. Trong năm học 2017-2018, nhóm giáo viên THT năm thứ nhất đã soạn hệ thống bài tập từ vựng ngữ pháp trực tuyến bổ trợ cho sinh viên năm thứ nhất và thử nghiệm vào tháng 4/2018.

- Đảm bảo hơn nữa công bằng giữa các sinh viên trong kiểm tra đánh giá. Giáo viên cần ý thức rằng nghiêm khắc trong thi cử không phải là "ác" với sinh viên mà là thực thi công bằng xã hội, một đòi hỏi của rất nhiều sinh viên, có như vậy mới giúp cho sinh viên có được thái độ học tập và thi cử nghiêm túc. Giáo viên cũng cần hợp tác hơn với sinh viên để giúp các em hoàn thành tốt bài thi Nói của mình, vì trong thi Nói năm thứ nhất thường có phần thi sinh viên phải đóng vai với giáo viên để hoàn thành một tình huống giao tiếp. 


\section{Kết luận}

Công tác đào tạo đại học hiện nay đang đứng trước những thách thức lớn về chất lượng. Quy trình giảng dạy cần được rà soát lại trong đó có kiểm tra đánh giá vì yếu tố này ảnh hưởng trực tiếp tới kết quả đầu ra của sinh viên và tác động ngược trở lại tới công tác dạy và học. Nghiên cứu về ý kiến phản hồi của người dạy và người học về công tác kiểm tra đánh giá môn $1 \mathrm{~A}+1 \mathrm{~B}, 2 \mathrm{~A}+2 \mathrm{~B}$ đã được tiến hành trên toàn bộ giáo viên dạy THT năm thứ nhất và 101 sinh viên năm thứ nhất của Khoa Ngôn ngữ và Văn hóa Pháp, ĐHNN - ĐHQGHN. Kết quả cho thấy nhìn chung, cả giáo viên và sinh viên đều có những phản hồi khá tích cực cả về nội dung và hình thức của công tác kiểm tra đánh giá THT năm thứ nhất năm học 20162017. Một số đề xuất nhằm làm nâng cao chất lượng kiểm tra đánh giá đã được đưa ra trong bài báo này, đã được áp dụng trong năm học 2017-2018 và sẽ được áp dụng trong những năm học tới. Trong tương lai, chúng tôi sẽ tiến hành phỏng vấn ngẫu nhiên sinh viên để có những phản hồi sâu và toàn diện hơn.

Nghiên cứu này được tiến hành theo yêu cầu của Ban chủ nhiệm Khoa Ngôn ngữ và Văn hóa Pháp và là khảo sát đầu tiên đánh giá thực trạng hoạt động kiểm tra đánh giá bộ môn THT ở Khoa theo chuẩn đầu ra, phục vụ cho công tác kiểm định chất lượng cũng như góp phần nâng cao chất lượng đào tạo của Khoa Ngôn ngữ và Văn hóa Pháp nói riêng và của ĐHNN - ĐHQGHN nói chung.

\section{Lời cảm ơn}

Xin trân trọng cảm ơn Trường Đại học Ngoại ngữ - Đại học Quốc gia Hà Nội, Ban chủ nhiệm Khoa Ngôn ngữ và Văn hóa Pháp, toàn thể các thầy cô dạy Thực hành tiếng năm thứ nhất $\mathrm{QH} 2016$ và các em sinh viên năm thứ nhất QH2016 đã giúp chúng tôi hoàn thành nghiên cứu này.

\section{Tài liệu tham khảo}

\section{Tiếng Việt}

Nguyễn Thúy Lan (2017). Một số tác động của bài thi đánh giá năng lực tiếng Anh theo chuẩn đầu ra đối với việc dạy tiếng Anh tại Trường Đại học Ngoại ngũ̃ - Đại học Quốc gia Hà Nội. Nghiên cứu Nước ngoài, 33(4), 122-136.

Nguyễn Thị Ngọc Quỳnh (2017). Kiểm tra đánh giá các môn học thành phần trong chương trình đào tạo theo chuẩn đầu ra ở trường ĐHNN-ĐHQGHN. Hội thảo Chuoong trình đào tạo theo chuẩn đầu ra và nhĩng huoóng đi mói, ĐHNN - ĐHQGHN, 26-32.

Nguyễn Thị Minh Tâm (2017). Công tác khảo sát ý kiến phản hồi của các bên liên quan về chương trình đào tạo. Hội thảo Chuoong trình đào tạo theo chuẩn đầu ra và nhũng huớng đi mói i, ĐHNN - ĐHQGHN, 47-77.

Nguyễn Quang Thuấn (2002). Xây dựng một công cụ kiểm tra đánh giá trong dạy và học ngoại ngữ. Tạp chi khoa hoc ĐHQGHN, 18(2), 23-31.

\section{Tiếng Anh}

ASEAN University Network (AUN) (2015). Guide to AUN Actual Quality Assessment at Programme Level version 3.0. AUN Secretariat, Bangkok, Thailand.

Bailey, K. M. (1996). Working for Washback: A Review of the Washback Concept in Language Testing. Language Testing, 13(3), 257-279.

Gibbs, G. and Simpson, C. (2005). Conditions Under Which Assessment Supports Students' Learning. Learning and Teaching in Higher Education (1), 3-31.

Miller, C. M. I \& Parlett, M. (1974). Up to the Mark: a study of the examination game, Guildford: Society for research into Higher Education.

Perrenoud, Ph. (1998). From Formative Evaluation to a Controlled Regulation of Learning Processes. Towards a wider conceptual field. Assessment in Education, 5(1), 85-102.

Snyder, B.R. (1971). The Hidden Curriculum. Cambridge, MA: MIT Press.

\section{Tiếng Pháp}

Conseil de l'Europe (2001). Cadre européen commun de référence pour les langues: apprendre, enseigner, évaluer. Paris: Didier.

Tagliante, C. (2005). L'évaluation et le Cadre européen commun. Paris: CLE International. 


\title{
TEACHERS AND LEARNERS' FEEDBACK ON THE ASSESSMENT OF 1A + 1B, 2A + 2B PROFICIENCY MODULES AT THE FACULTY OF FRENCH LANGUAGE AND CULTURE, UNIVERSITY OF LANGUAGES AND INTERNATIONAL STUDIES - VIETNAM NATIONAL UNIVERSITY, HANOI
}

\begin{abstract}
Do Thi Bich Thuy
Faculty of French Language and Culture, VNU University of Languages and International Studies,

Pham Van Dong, Cau Giay, Hanoi, Vietnam

Abstract: This study presents the results of a teachers and learners' feedback survey on the assessment of $1 \mathrm{~A}+1 \mathrm{~B}, 2 \mathrm{~A}+2 \mathrm{~B}$ proficiency modules in the academic year 2016-2017 at the Faculty of French Language and Culture, University of Languages and International Studies Vietnam National University, Hanoi. The survey found that teachers and students had positive feedbacks on the assessment quality of $1 \mathrm{~A}+1 \mathrm{~B}, 2 \mathrm{~A}+2 \mathrm{~B}$ language modules, and especially appreciated the variety of assessment methods as well as the fact that the results were returned to the students in time for them to improve their learning. The article also offers some suggestions for enhancing the effectiveness of proficiency assessment.
\end{abstract}

Keywords: teachers' feedbacks, students' feedbacks, assessment, proficiency, French

\section{PHỤ LỤC PHIẾU ĐIỀU TRA Ý KIẾN PHẢN HỔI VỀ CÔNG TÁC KIỂM TRA ĐÁNH GIÁ}

Kính chào các thầy cô/ em! Kết thúc năm thứ nhất, tổ tiếng Pháp 1 tiến hành lấy ý kiến phản hồi của các thầy cô/ em về chương trình đào tạo và kiểm tra đánh giá ở các môn $1 \mathrm{~A}+1 \mathrm{~B}, 2 \mathrm{~A}+$ 2B. Các đánh giá chân thực của các thầy cô/ em sẽ là cơ sở để tổ có những điều chỉnh nâng cao chất lượng giảng dạy thực hành tiếng. Xin cảm ơn các thầy cô/ em!

1. Sau khi nhận được đề cương môn học $1 \mathrm{~A}+1 \mathrm{~B}$, thầy cô/ em có đọc không? Có

Nếu không đọc, xin cho biết lý do?

Không

2. Sau khi nhận được lịch trình môn học $1 \mathrm{~A}+1 \mathrm{~B}$, thầy cô/ em có đọc không?

Có

Không

Nếu không đọc, xin cho biết lý do?

3. Sau khi nhận được đề cương môn học $2 \mathrm{~A}+2 \mathrm{~B}$, thầy cô/ em có đọc không?

Có

Nếu không đọc, xin cho biết lý do?

Không

4. Sau khi nhận được lịch trình môn học $2 \mathrm{~A}+2 \mathrm{~B}$, thầy cô/ em có đọc không? 
Nếu không đọc, xin cho biết lý do?

Hãy đánh dấu $\mathrm{X}$ vào ô mà thầy cô/ em cho là phù hợp nhất trong 4 mức đánh giá: Rất tốt, Tốt, Trung bình, Kém.

\begin{tabular}{|c|c|c|c|c|}
\hline & $\begin{array}{c}\text { Rất tốt } \\
\text { (4) }\end{array}$ & $\begin{array}{l}\text { Tốt } \\
\text { (3) }\end{array}$ & $\begin{array}{l}\text { Trung bình } \\
\text { (2) }\end{array}$ & $\begin{array}{c}\text { Kém } \\
(1)\end{array}$ \\
\hline $\begin{array}{l}\text { Việc đánh giá kết quả học tập được thiết kế dựa trên } \\
\text { chuần đầu ra môn học } 1 \mathrm{~A}+1 \mathrm{~B} \text {. }\end{array}$ & & & & \\
\hline $\begin{array}{l}\text { Việc đánh giá kết quả học tập được thiết kế dựa trên } \\
\text { chuẩn đầu ra môn học } 2 \mathrm{~A}+2 \mathrm{~B} \text {. }\end{array}$ & & & & \\
\hline $\begin{array}{l}\text { Các quy định về đánh giá kết quả học tập môn học } 1 \mathrm{~A} \\
+1 \mathrm{~B} \text { của người học (bao gồm thời gian, phương pháp, } \\
\text { tiêu chí, trọng số, dạng thức, nội dung) rõ ràng và được } \\
\text { thông báo công khai tới người học. }\end{array}$ & & & & \\
\hline $\begin{array}{l}\text { Các quy định về đánh giá kết quả học tập môn học } 2 \mathrm{~A} \\
+2 \mathrm{~B} \text { của người học (bao gồm thời gian, phương pháp, } \\
\text { tiêu chí, trọng số, dạng thức, nội dung) rõ ràng và được } \\
\text { thông báo công khai tới người học. }\end{array}$ & & & & \\
\hline $\begin{array}{l}\text { Phương pháp đánh giá kết quả học tập môn học } 1 \mathrm{~A}+ \\
\text { 1B đa dạng (kiểm tra thường xuyên, kiểm tra giữa kì, thi } \\
\text { cuối kì, trắc nghiệm khách quan, tự luận...) }\end{array}$ & & & & \\
\hline $\begin{array}{l}\text { Phương pháp đánh giá kết quả học tập môn học } 2 \mathrm{~A}+ \\
\text { 2B đa dạng (kiểm tra thường xuyên, kiểm tra giữa kì, thi } \\
\text { cuối kì, trắc nghiệm khách quan, tự luận...) }\end{array}$ & & & & \\
\hline $\begin{array}{l}\text { Các bài kiểm tra môn } 1 \mathrm{~A}+1 \mathrm{~B} \text { đảm bảo kiểm tra được } \\
\text { những kĩ năng và kiến thức đã được dạy và học. }\end{array}$ & & & & \\
\hline $\begin{array}{l}\text { Các bài kiểm tra môn } 2 \mathrm{~A}+2 \mathrm{~B} \text { đảm bảo kiểm tra được } \\
\text { những kĩ năng và kiến thức đã được dạy và học. }\end{array}$ & & & & \\
\hline $\begin{array}{l}\text { Các bài kiểm tra môn } 1 \mathrm{~A}+1 \mathrm{~B} \text { đảm bảo tính công bằng } \\
\text { giữa các sinh viên. }\end{array}$ & & & & \\
\hline $\begin{array}{l}\text { Các bài kiểm tra môn } 2 \mathrm{~A}+2 \mathrm{~B} \text { đảm bảo tính công bằng } \\
\text { giữa các sinh viên. }\end{array}$ & & & & \\
\hline $\begin{array}{l}\text { Kết quả đánh giá môn } 1 \mathrm{~A}+1 \mathrm{~B} \text { được trả lại cho sinh } \\
\text { viên kịp thời để người học cải thiện việc học tập. }\end{array}$ & & & & \\
\hline $\begin{array}{l}\text { Kết quả đánh giá môn } 2 \mathrm{~A}+2 \mathrm{~B} \text { được trả lại cho sinh } \\
\text { viên kịp thời để người học cải thiện việc học tập. }\end{array}$ & & & & \\
\hline
\end{tabular}

17. Nếu kết quả các bài kiểm tra hay thi của sinh viên chưa tốt như thầy cô/ em mong muốn, xin cho biết lí do là vì sao (số 1 là lí do quan trọng nhất):

1.

2.

3.

18. Thầy cô/ em có các đề xuất gì liên quan đến kiểm tra đánh giá:

Xin trân trọng cảm ơn những ý kiến đóng góp quý báu của thầy cô /em! 